\title{
Conidium Production by Higher Fungi within Thin Layers of Liquid Paraffin: a Slide-culture Technique
}

\author{
By M. F. MADELIN \\ Department of Botany, University of Bristol
}

(Accepted for publication 15 October 1968)

\begin{abstract}
SUMMARY
A new slide culture technique is described in which 18 of 34 higher fungi tested sporulated asexually within a thin layer of liquid paraffin, some normally, some more or less abnormally. The oil greatly facilitated observation of the developing structures at high magnifications. The technique promises to be of use in studies of development in higher fungi.
\end{abstract}

\section{INTRODUCTION}

Conventional slide cultures (e.g. Smith, 1960) are extremely useful for studying the course of development of fungi but present a number of disadvantages when sustained observation beneath the microscope is proposed. These include the appearance of condensation droplets on the cover glass which seriously obscure vision; the proneness of the small closed system to rapid temperature changes which affect relative humidity and so tend to interfere with the fungus's development; and the difficulty of observing changes inside living cells that are surrounded by air. Observation of the development or behaviour of aquatic fungi is by contrast relatively easy because of the aqueous medium in which such fungi can be immersed while they are being observed. Unfortunately, relatively few subaerial moulds sporulate readily when immersed in aqueous solutions. Submerged sporulation has been recorded in species of the genera Penicillium, Aspergillus, Fusarium, Curvularia, and a number of other moulds under narrowly defined conditions (Vézina, Singh \& Sehgal, 1965, and references therein; Capellini \& Peterson, 1965), but Vézina et al. noted that in general a medium that is found to be optimal for sporulation of one species is not necessarily good for another, even when closely related. The absence of a fairly general method for obtaining submerged sporulation has prevented the development of a convenient general slide culture technique based on sporulation of moulds in liquids.

Consideration was therefore given to the possibility that moulds might sporulate if the immersion liquid was hydrophobic. An obvious candidate for such trials was liquid paraffin, or light mineral oil. Many records testify to its general innocuousness. It has been widely used for the preservation of stock cultures of bacteria and moulds and has also been advocated for the conservation of plant tissue cultures (Caplin, 1959). Stock cultures of moulds beneath oil may even sporulate during storage (Buell \& Weston, 1947). Certain other micro-organisms whose reproductive development is normally subaerial are able to fructify when covered by liquid paraffin, for example, the cellular slime mould Dictyostelium mucoroides (Potts, 1902) and the myxobacterium Chondromyces crocatus (Quinlan \& Raper, 1965). In experiments on the phototropism

Vol. 55, No. 2, was issued 27 February 1969 
of sporangiophores of Phycomyces blakesleeanus (Buder, 1918; Banbury, 1952) and on the growth of conidiophores of Aspergillus giganteus (Trinci \& Banbury, 1967) specialized hyphae were immersed in liquid paraffin and still continued to grow. A layer of liquid paraffin is not a barrier to respiratory gas exchange. Edwards, Buell \& Weston (1947) obtained results which suggested that even I cm. depth of mineral oil permits sufficient respiration of Sordaria fimicola for it to survive a long time, and showed that beneath $5 \mathrm{~mm}$. of oil its respiration rate was still more than one fifth of the rate in controls. Further, Caplin (1959) has pointed out that the solubility of oxygen in light mineral oil at $38^{\circ}$ is four times that in water at the same temperature, and that the solubilities are probably in the same proportion at lower temperatures.

Attempts were therefore made to devise a simple system in which a good range of subaerial higher fungi would sporulate in mineral oil in a culture cell of such a construction that high power microscope objectives could be used for critical observation of the details of development.

\section{METHODS}

The mineral oil used in these experiments was liquid paraffin, light, specific gravity $0.830-0.870$ (British Drug Houses, Ltd., Poole, Dorset). It was sterilized in approximately $15 \mathrm{ml}$. lots in capped test tubes by autoclaving at $15 \mathrm{lb}$./in. ${ }^{2}$ for $20 \mathrm{~min}$. and was left for several weeks before use. The Cellophane was type PT 300 manufactured by British Cellophane Ltd., Bridgwater, Somerset. Transparent polythene sheeting was $60 \mu$ thick, and was derived from the polybags in which sterile disposable Petri dishes are supplied. The fungi used were isolates held in the Botany Department, University of Bristol.

\section{Technique for preparing mineral oil slide cultures}

After preliminary tests, the culture cell illustrated in Fig. I was developed. The requirements which are met in its design are: (I) that the fungus should be visible through a thin, plane cover-glass; (2) that there should be no air space between the developing organism and the cover glass that would hamper observation; (3) that aeration should be provided by arranging the shortest possible diffusion path to an air space; (4) that the culture cell should be stable enough to withstand normal handling; (5) that the fungus and its substrate should not be able to dry during protracted incubation.

The procedure for preparing slide cultures of the type figured is as follows. (I) Wash, polish, and flame-sterilize slide $(76 \times 25 \mathrm{~mm}$.) and cover-glass $(50 \times 22 \mathrm{~mm}$.). (2) Apply a worm of petroleum jelly around cover-glass, close to the side edges, but set back about $5 \mathrm{~mm}$. from each end to facilitate handling with forceps; the worm is delivered from a hypodermic syringe fitted with a cannula about $\mathrm{I} \cdot 3 \mathrm{~mm}$. internal diameter. (3) Place a small drop (about $5 \mathrm{~mm}$. diam.) of molten nutrient agar (e.g. malt extract or potato extract) about $17 \mathrm{~mm}$. from one end of the cover-glass with a sterile glass rod. (4) Inoculate the agar drop centrally with the fungus. (5) Use a sterile glass dropper to place one or two small drops of sterile liquid paraffin on the agar drop. (6) Cover the oil and agar with a $16 \mathrm{~mm}$. square of either Cellophane or polythene sheeting (see below) which has been sterilized by immersion in boiling water. Adherent water droplets must be shaken off before the membrane is laid over the oil. Avoid trapping air bubbles. (7) Place a $13 \mathrm{~mm}$. square of damp filter paper on the slide with its centre 
about $20 \mathrm{~mm}$. from one end. (8) Invert the cover-glass over the slide and gently press it down to complete the petroleum jelly seal which should be about I mm. thick. An air space must remain between the membrane and the slide beneath.

Squares of membrane filter have been tested for use as membranes in these cultures but proved unsatisfactory. The immersion of Cellophane squares in boiling water to sterilize them served additionally to wash out a constituent that was inhibitory to the sporulation of certain fungi.

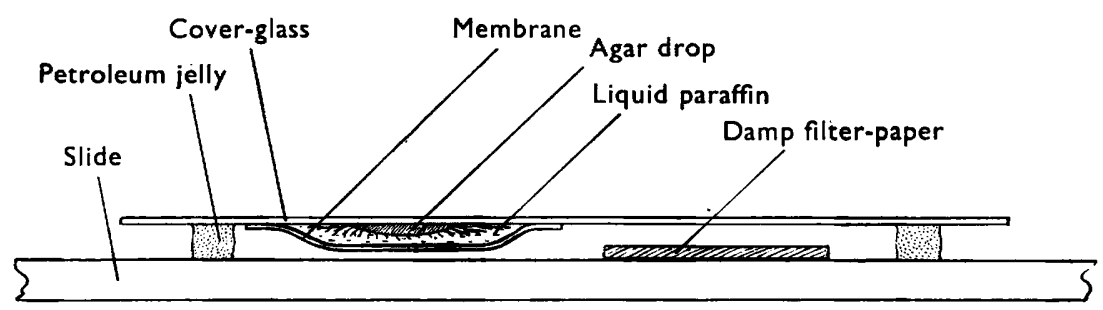

Fig. I. Diagrammatic median section of slide culture (not to scale).

\section{RESULTS AND DISCUSSION}

The mineral oil slide-culture technique was applied to a series of fungi with the results shown in Table $I$. The cultures were incubated at room temperature and examined frequently over a period of up to 2 weeks. Asexual spores were formed by 18 of the 34 fungi tested, usually when the culture was only a few days old. Negative results recorded in Table I may not signify that sporulation of the species in question is unobtainable with this technique, for all combinations of the two media and the two gas-permeable membranes were not applied to all species, nor was the range of possible cultural conditions explored. Other conditions of nutrition, temperature, illumination, and even of relative humidity within the culture cells might prove suitable for other species.

The reason for a membrane of a particular composition being suitable for sporulation of some species but not others is not clear from the results to hand. One possibility is that a given membrane leads to a critical favourable degree of aeration in the slide culture, but a more likely one is that cellophane acts as a nutrient for certain of the fungi and interferes with their sporulation. Alternaria brassicicola and Alternaria sp. I were both seen to grow through the cellophane membrane, beneath which neither sporulated. However, at least the former sporulated when the membrane was one of polythene.

In most of the fungi in which asexual sporulation occurred it appeared to be essentially normal (see, for example, P1. I, fig. I-6). The conidia of Acrospeira levis developed normally at first, but the appearance of a gas phase within almost all the spores as they aged was a slightly unusual feature (P1. I, fig. 8). Old and dry spores of this species from conventional agar slant cultures sometimes contain a gas phase that rapidly disappears after the spores are re-wetted, but they are a minority. A similar gas phase that appeared normally within drying ascospores of Sordaria fimicola, Pleurage curvicolla and Hypoxylon fuscum was reported by Ingold (1956). More pronounced morphological abnormalities were shown by some conidiophores of some of the aspergilli tested. It was not uncommon for a smaller or greater number of 
Table I. The production or otherwise of asexual spores by different higher fungi cultivated beneath liquid paraffin in slide cultures in which different combinations of culture media and gas-permeable membranes were employed

$$
\begin{array}{ll}
\mathrm{MA}=3 \% \text { malt extract agar } & \mathbf{P A}=\text { potato extract agar } \\
\mathrm{C}=\text { Cellophane membrane } & \mathbf{P}=\text { polythene membrane }
\end{array}
$$

\begin{tabular}{|c|c|c|c|}
\hline Species & Sporulation & $\begin{array}{l}\text { Medium/membrane } \\
\text { combinations } \\
\text { allowing sporulation }\end{array}$ & $\begin{array}{l}\text { Medium/membrane } \\
\text { combinations not allowing } \\
\text { sporulation }\end{array}$ \\
\hline Acrospeira levis & + & $\mathrm{MA} / \mathrm{C}, \mathrm{PA} / \mathrm{P}$ & \\
\hline Alternaria brassicicola & + & & $\mathrm{MA} / \mathrm{C}, \mathrm{PA} / \mathrm{C}$ \\
\hline $\begin{array}{l}\text { Alternaria brassicicola } \\
\text { (albino mutant) }\end{array}$ & - & & $\mathrm{MA} / \mathrm{C}$ \\
\hline Alternaria sp. I & + & $\mathrm{MA} / \mathrm{C}$ & $\mathbf{P A} / \mathbf{P}$ \\
\hline Alternaria sp. II & - & & $\mathrm{MA} / \mathrm{C}, \mathrm{PA} / \mathrm{C}$ \\
\hline Aspergillus flavus & + & $\mathrm{MA} / \mathrm{C}$ & \\
\hline Aspergillus niger & + & MA/P & MA/C \\
\hline Aspergillus ochraceus & - & . & MA/C \\
\hline Aspergillus oryzae & - & & $\mathrm{MA} / \mathrm{C}$ \\
\hline Aspergillus repens & + & MA/C, MA/P & • \\
\hline Aspergillus tamarii & + & $\mathbf{M A} / \mathrm{C}, \mathrm{PA} / \mathbf{P}$ & \\
\hline Aspergillus versicolor & - & 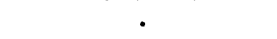 & MA/C, MA/P \\
\hline Botrytis cinerea & - & . & $\mathrm{MA} / \mathrm{C}, \mathbf{P A} / \mathrm{C}, \mathrm{PA} / \mathrm{P}$ \\
\hline Cephaliophora tropica & - & & $\mathrm{PA} / \mathrm{C}$ \\
\hline Cephalosporium sp. & + & $\mathrm{MA} / \mathrm{C}$ & • \\
\hline Cératostomella adiposa & + & MA/P & MA/C \\
\hline Fusarium roseum & - & & $\mathrm{MA} / \mathrm{C}$ \\
\hline Fusarium solani & + & $\mathrm{MA} / \mathrm{C}$ & . \\
\hline Fusarium sp. & - & 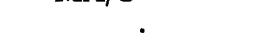 & $\mathrm{MA} / \mathrm{C}$ \\
\hline Neurospora crassa & & & \\
\hline Macroconidia & - & & $\mathrm{MA} / \mathrm{C}, \mathrm{MA} / \mathrm{P}, \mathrm{PA} / \mathrm{C}, \mathrm{PA} / \mathrm{P}$ \\
\hline Microconidia & + & $\mathrm{MA} / \mathrm{P}, \mathrm{PA} / \mathrm{C}$ & $\mathrm{MA} / \mathrm{C}, \mathrm{PA} / \mathrm{P}$ \\
\hline Oedocephalum roseum & - & & $\mathrm{PA} / \mathrm{C}$ \\
\hline Penicillium brevicompactum & + & $\mathrm{PA} / \mathrm{C}$ & MA/C \\
\hline Penicillium cyclopium & + & MA/C & • \\
\hline Penicillium frequentans & - & 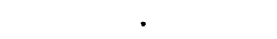 & $\mathrm{MA} / \mathrm{C}$ \\
\hline Penicillium janthinellum & - & . & $\mathrm{MA} / \mathrm{C}$ \\
\hline Penicillium luteum & - & & $\mathrm{PA} / \mathrm{C}$ \\
\hline Penicillium notatum & + & $\mathrm{MA} / \mathrm{C}, \mathrm{PA} / \mathrm{C}$ & $-0-1$ \\
\hline Penicillium sp. & + & $\mathrm{MA} / \mathrm{C}$ & \\
\hline Sclerotinia fructigena & - & . & $\mathrm{MA} / \mathrm{C}, \mathrm{MA} / \mathbf{P}$ \\
\hline Stachybotrys atra & - & & MA/C, MA/P, PA/P \\
\hline Stemphylium sp. & + & $\mathbf{M A} / \mathbf{C}$ & 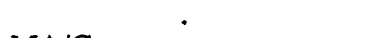 \\
\hline Trichoderma viride & - & & $\mathrm{MA} / \mathrm{C}$ \\
\hline Trichothecium roseum & + & MA/C & • \\
\hline Wardomyces pulvinata & + & MA/C & . \\
\hline
\end{tabular}

phialides on a conidiophore to proliferate as hyphae (Pl. I, fig. 7) or even as small aberrant conidiophores. Spores in Penicillium brevicompactum and $P$. notatum were formed singly or in only small numbers on each phialide, and the conidiophores were only sparsely branched. Botrytis cinerea produced no conidia but formed many sclerotial initials whose processes of development were clearly displayed (cf. Townsend \& Willetts, 1954). Three additional sclerotial or microsclerotial species were tested for growth beneath oil in MA/C cultures (see Table I for abbreviations), namely Rhizoctonia solani, Sclerotium rolfsii and Papulaspora rubida, but none formed sclerotia. Neurospora crassa (Lindegren stock, Lr6a) formed microconidia but not macro- 
conidia beneath oil. Protoperithecia were formed, most abundantly in MA/C and PA/P cultures, but no attempts were made to spermatize them and observe their further development. Three Zygomycetes also were grown in MA/C cultures, namely Rhizopus sexualis, Conidiobolus villosus, and Thamnidium elegans but none formed spores.

Oil-immiscible droplets of a presumably watery exudate were sometimes formed on hyphae or conidiophores growing through the liquid paraffin, or on developing spores or sclerotial initials. Some can be seen in Pl. I, fig. 4, and fig. 6 shows a thin layer of exudate that invests the spores joined together in a single chain. Trinci \& Banbury (1967) observed similar droplets on conidiophores of Aspergillus giganteus when immersed in liquid paraffin, but were uncertain whether the droplets played a specific role in the growth of the conidiophores. They suggested that they were comparable with guttation droplets formed on the leaves of plants under conditions of high turgor in a saturated atmosphere.

Tests of this slide-culture technique thus suggest that the ability to sporulate asexually beneath thin layers of mineral oil is probably fairly common among higher fungi, and therefore that the technique is likely to prove useful in studies of their development, especially where photomicrographic records are required, as for example in quantitative studies of developmental processes.

\section{REFERENCES}

Banbury, G.H. (1952). Physiological studies in the Mucorales. Part I. The phototropism of sporangiophores of Phycomyces blakesleeanus. J. exp. Bot. 3, 77.

BuDER, J. (1918). Die Inversion des Phototropismus bei Phycomyces. Ber. dt. bot. Ges. 36, 104.

Buel, C. B. \& Weston, W. H. (1947). Application of the mineral oil conservation method to maintaining collections of fungous cultures. Am. J. Bot. 34, 555 .

CAPLIN, S. M. (1959). Mineral oil overlay for conservation of plant tissue cultures. Am. J. Bot. 46, 324.

Cappellin, R. A. \& Peterson, J. L. (1965). Macroconidium formation in submerged cultures by a non-sporulating strain of Gibberella zeae. Mycologia 57, 962.

EdWARDS, G. A., Buell, C. B. \& Weston, W.H. (1947). The influence of mineral oil on the oxygen consumption of Sordaria fimicola. Am. J. Bot. 34, 55I.

INGOLD, C. T. (1956). A gas phase in viable fungal spores. Nature, Lond. 177, 1242.

Potrs, G, (1902). Zur physiologie des Dictyostelium mucoroides. Flora, Jena 91, 281.

QUINLAN, M. S. \& RAPER, K. B. (1965). Development of the myxobacteria. In Encyclopedia of Plant Physiology. Ed. by W. Ruhland, vol. 15, part 1, p. 596. Berlin, Heidelberg and New York: Springer-Verlag.

SMrTH, G. (1960). An Introduction to Industrial Mycology, 5th ed. London: Edward Arnold (Publishers) Ltd.

TOWNSEND, B. B. \& Willetrs, H. J. (1954). The development of sclerotia of certain fungi. Trans. Br. mycol. Soc. 37, 213.

Trincl, A. P. J. \& BanBury, G. H. (1967). A study of the growth of the tall conidiophores of Aspergillus giganteus. Trans. Br. mycol. Soc. 5, 525.

Vézina, C., Singh, K. \& SeHgal, S. N. (1965). Sporulation of filamentous fungi in submerged culture. Mycologia 57, 722. 


\section{EXPLANATION OF PLATE}

Fig. 1. Trichothecium roseum. $\quad \times 600$.

Fig. 2. Ceratostomella adiposa. $\quad \times 700$.

Fig. 3. Alternaria sp. I. $\quad \times 870$.

Fig. 4. Alternaria sp. II. $\times 350$.

Fig. 5. Wardomyces pulvinata. $\times 1040$.

Fig. 6. Aspergillus tamarii. $\quad \times 700$.

Fig. 7. Aspergillus repens. $\quad \times 335$.

Fig. 8. Acrospeira levis. $\quad \times 870$. 
Journal of General Microbiology, Vol. 55, No. 3

Plate I
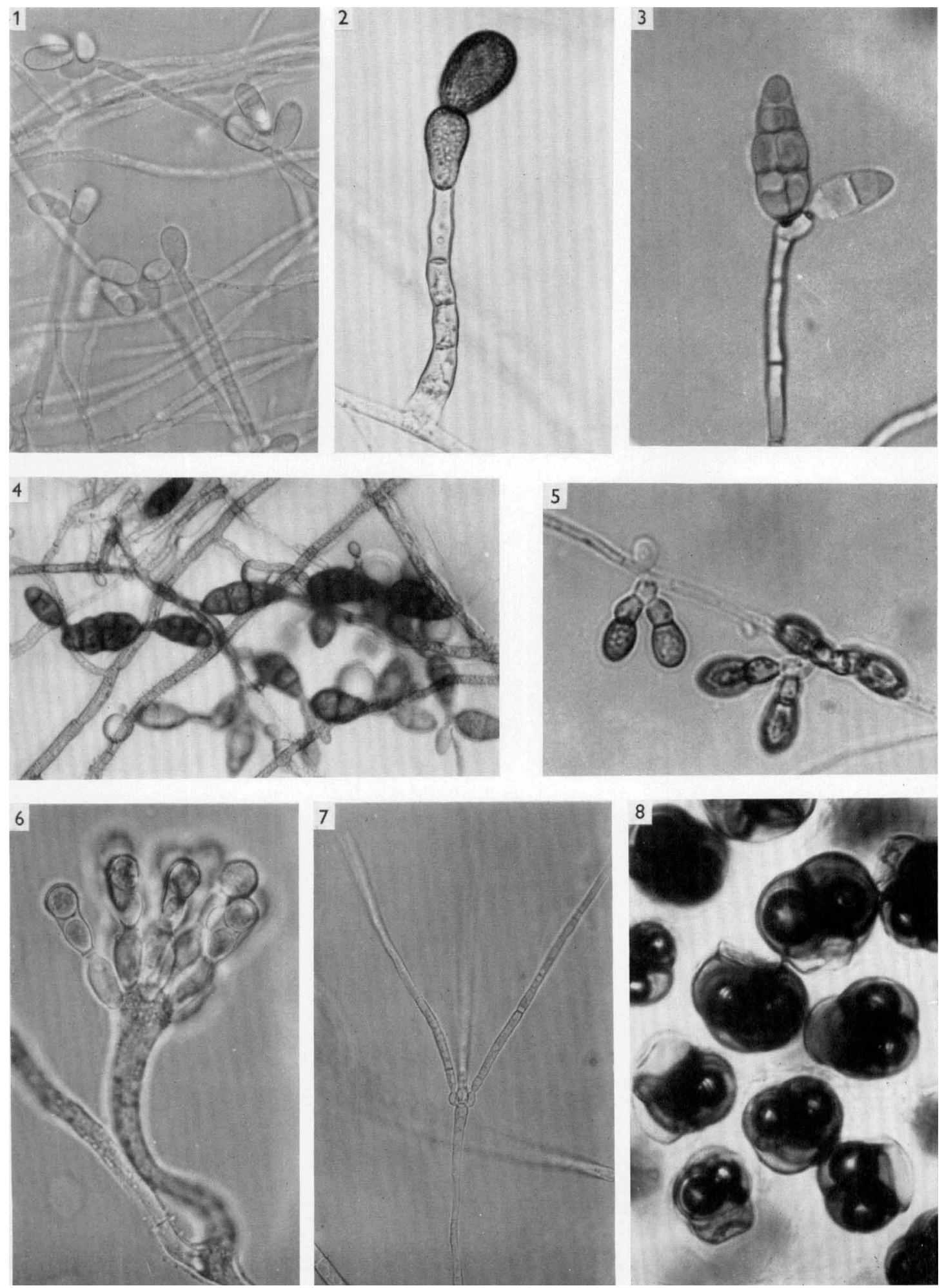